\title{
Effect of diallyl disulfide and garlic oil on different human astrocytoma cell lines
}

\author{
ANNA CHOROMANSKA ${ }^{1}$, JULITA KULBACKA ${ }^{1}$, JOLANTA SACZKO $^{1}$ and PAWEL SUROWIAK ${ }^{2}$ \\ ${ }^{1}$ Department of Molecular and Cellular Biology, Faculty of Pharmacy, Wroclaw Medical University, 50-556 Wroclaw; \\ ${ }^{2}$ Department of Histology and Embryology, Faculty of Medicine, Wroclaw Medical University, 50-368 Wroclaw, Poland
}

Received January 31, 2020; Accepted June 30, 2020

DOI: $10.3892 / b r .2020 .1339$

\begin{abstract}
Gliomas are a group of malignant brain tumors. Despite significant efforts to optimize treatment options for patients with high-grade glioma, the prognosis of the overwhelming majority of patients remain poor. This bleak prognosis despite treatment of the glioma, is partly due to the tendency of therapeutics to diffusely penetrate into the neighboring brain tissues, but also due to the innate resistance of these tumors to chemotherapy and radiation. Garlic contains water-soluble and oil-soluble sulfur compounds. The oil-soluble compounds, including diallyl sulfide, diallyl disulfide (DADS), diallyl trisulfide and ajoene, are more effective potential anti-cancer treatments than the water-soluble compounds. There are several studies examining the effects of oil-soluble compounds on various types of cancer cells, although, to the best of our knowledge, there are no studies examining the effects of these compounds on glioma cells. The aim of the present study was to investigate the potential anti-glioma properties of DAD and garlic oil on proliferation and induction of apoptosis in four different types of glioma cell lines representative of different grades of the disease. The results showed that garlic oil exhibits favorable anti-cancer potential towards gliomas of various degrees of differentiation.
\end{abstract}

\section{Introduction}

Gliomas are a group of malignant brain tumors, and despite the significant efforts that have been made to develop and optimize novel therapeutics for treatment of patients with high-grade glioma, the prognosis of these patients remains poor (1). Surgery is often incomplete due to the inaccessibility of the tumor location. Additionally, glioma cells are often resistant to chemotherapy and radiation (2). Thus, novel treatment

Correspondence to: Dr Anna Choromanska, Department of Molecular and Cellular Biology, Faculty of Pharmacy, Wroclaw Medical University, Borowska 211A, 50-556 Wroclaw, Poland

E-mail: anna.choromanska@umed.wroc.pl

Key words: glioma, diallyl disulfide, garlic oil, apoptosis, natural therapeutics strategies are required. The use of compounds of natural origin may serve as an alternative method of treatment. The health-promoting and healing properties of garlic have been used for thousands of years. Garlic contains several water- and oil-soluble organosulfur compounds which have conditioning properties, such as antimicrobial, antithrombotic, antiarthritic and antitumor properties (3). Oil-soluble compounds which include: Diallyl sulfide (DAS), diallyl disulfide (DADS), diallyl trisulfide (DATS) and ajoene are more effective than the water-soluble compounds when used to prevent or treat cancer. DADS and DATS are the primary components of garlic oil, which has a yellowish hue, and is insoluble in water (1).

A number of studies have focused on the evaluation of the impact of DADS on the human body in health and disease. These studies have shown that DADS exhibits protective properties and at the same time target cancer cells $(4,5)$. In vivo studies have shown that DADS effectively inhibits carcinogens by modulating the action of cytochrome P450-dependent monooxygenases, as well as by affecting the activation of phase II enzymes which are responsible for detoxifying xenobiotics (6). These include glutathione reductase and glutathione transferase (7).

The anti-proliferative properties of DADS are related to its ability to decrease the proportion of cells in the G1 and G2/M phases (8). Furthermore, several studies have suggested that DADS may induce apoptosis in several types of cancer cells, and can work as an inhibitor of histone deacetylase $(3,4,9)$. Previous studies have suggested that the above mentioned abilities reduce cell proliferation (10), angiogenesis, as well as invasion and metastasis in cancer cells (9). A number of studies have demonstrated the chemopreventative properties of different forms of products and compounds derived from garlic, including fresh and aged garlic extract, as well as garlic oil (11). The anti-cancer properties of garlic oil is attributed to the presence of organic sulfur compounds in garlic. The modes of organic sulfur action include its effect on drug metabolizing enzymes, antioxidant properties and tumor growth inhibition (12). Therefore, the consumption of garlic may assist in cancer prevention, while the use of specific compounds derived from garlic may increase the therapeutic potential in regard to cancer prevention or even treat existing cancers. The effectiveness of these compounds has been demonstrated in several studies on various cancer cell lines including breast, colon and prostate cancer cells (13); however, 
its effects have not been studied on human glioblastoma cells, to the best of our knowledge. Taking into consideration the above, the aim of the present study was to determine whether oil-soluble organosulfur compounds derived from garlic exhibited anti-cancer activity against human glioma cells. The effect of DADS and garlic oil (which is a combination of several oil-soluble organosulfur compounds) were assessed on cell viability and apoptosis induction. The effects were assessed on four different glioma cell lines of different grades.

\section{Materials and methods}

Cell culture. In the present study, four human astrocytoma cell lines of differing grades were used: CCF-STTG1 (grade IV, astrocytoma), SW1783 (grade III, astrocytoma), SW1088 (astrocytoma) and CHLA-03-AA (anaplastic astrocytoma). All cell lines were purchased from ATCC ${ }^{\circledR}$. SW1783 and SW1088 cells were grown as a monolayer in ATCC-formulated Leibovitz's L-15 medium (cat. no. 30-2008; ATCC) supplemented with $10 \% \mathrm{FBS}$ and $50 \mu \mathrm{g} / \mathrm{ml}$ streptomycin (Sigma-Aldrich; Merck $\mathrm{KGaA})$. These two cell lines were grown at $37^{\circ} \mathrm{C}$ in $100 \%$ air. For CCF-STTG1 and CHLA-03-AA cells, ATCC-formulated RPMI-1640 medium (catalog no. 30-2001; ATCC) supplemented with $10 \%$ FBS and $50 \mu \mathrm{g} / \mathrm{ml}$ streptomycin was used. These cells were grown at $37^{\circ} \mathrm{C}$ with $5 \% \mathrm{CO}_{2}$. Prior to each experiment, the cells were detached using $0.25 \%$ trypsin with $0.02 \%$ EDTA (Sigma-Aldrich; Merck KGaA).

Chemicals. Garlic oil and DADS was purchased from Sigma-Aldrich; Merck KGaA (cat. no. 8000-78-0 and SMB00378, respectively). A range of concentrations of both chemicals were used in the present study $(0.015-150 \mu \mathrm{g} / \mathrm{ml})$. Both garlic oil and DADS were diluted in the appropriate culture medium for each cell line.

MTT assay and determination of the $I C_{50}$. The viability of cells was determined using an MTT assay (Sigma-Aldrich; Merck $\mathrm{KGaA}$ ) after $24 \mathrm{~h}$ of incubation with different concentrations of garlic oil and DADS $(0,015-150 \mu \mathrm{g} / \mathrm{ml})$. To assess the effect of garlic oil, concentrations of 15 and $150 \mu \mathrm{g} / \mathrm{ml}$ were used, the results obtained were not included in the determination of cell viability and $\mathrm{IC}_{50}$, as the absorbance obtained in those samples was clearly overvalued due to the presence of the separate oil layer in the suspension.

The MTT assay was used for evaluation of mitochondrial metabolic function according to the manufacturer's protocol (Sigma-Aldrich; Merck KGaA). A total of $1 \times 10^{4}$ cells/well were seeded into 96-well microculture plates. The absorbance was determined using an Enspire Multiplate reader spectrophotometer at $570 \mathrm{~nm}$ (Perkin Elmer, Inc.). Mitochondrial metabolic function was expressed as a percentage of the viable treated cells to the untreated control cells. Based on the viability values obtained in the MTT assay, the $\mathrm{IC}_{50}$ values for DADS and garlic oil were calculated using GraphPad Prism version 7.03 (GraphPad Software, Inc.).

Evaluation of apoptosis and necrosis. Annexin V conjugated to fluorescein isothiocyanate (FITC) fluorochrome was used for flow cytometry analysis of cells which were undergoing apoptosis. Staining with Annexin V/FITC was performed at
Table I. $\mathrm{IC}_{50}$ values of DADS and garlic oil in glioma cell lines.

\begin{tabular}{llc}
\hline & \multicolumn{2}{c}{$\mathrm{IC}_{50}, \mu \mathrm{g} / \mathrm{ml}$} \\
\cline { 2 - 3 } Cell lines & DADS & Garlic oil \\
\hline CCF STTG1 & 5.8 & 4.05 \\
SW1783 & Non-toxic & 1.11 \\
SW1088 & Non-toxic & 0.15 \\
CHLA-03-AA & 2.64 & 0.072
\end{tabular}

DADS, diallyl disulfide.

room temperature for $15 \mathrm{~min}$. The externalization of phosphatidylserine occurs during the early stages of apoptosis, and Annexin V/FITC staining can identify apoptosis at an earlier stage than assays based on nuclear changes, such as DNA fragmentation (13). Necrotic changes were identified using propidium iodide (PI), fluorescence of which is enhanced 20-30-fold upon binding to nucleic acids (13). The analysis was performed using a commercial FITC Annexin V kit (BioLegend, Inc.; cat. no. 640914). For evaluation of apoptosis and necrosis, $0.15,0.75$ and $1.5 \mu \mathrm{g} / \mathrm{ml}$ DADS or garlic oil were used. Analysis was performed using CyFlow Cube 6 cytometer (Sysmex Europe, GmbH), where FL-1 was used for Annexin-V-FITC and FL-2 detector was used for necrotic cells (PI stained) measurements. A representative example of the gating strategy used in each experiment is shown in Fig. 1. In the quadrant gates, Q1, Q2, Q3 and Q4 fields correspond respectively to necrotic, late-apoptotic, alive cells and early apoptotic cells.

Statistical analysis. Data were analyzed using GraphPad Prism version 7.03. A two-way ANOVA followed by a post-hoc Tukey's test was used to compare the data were $\alpha=0.05$. All samples were analyzed in triplicate. $\mathrm{P}<0.05$ was considered to indicate a statistically significant difference.

\section{Results}

Cell viability analysis showed that the highest assessed DADS concentrations (15 and $150 \mu \mathrm{g} / \mathrm{ml})$ were cytotoxic for CCF-STTG1 and CHLA-03-AA cells (Fig. 2). $\mathrm{IC}_{50}$ for CCF-STTG1 and CHLA-03-AA cells were 5.8 and $2.64 \mu \mathrm{g} / \mathrm{ml}$, respectively (Table I). For SW1783 and SW1088 cells, DADS was not cytotoxic and even the highest tested concentration- $150 \mu \mathrm{g} / \mathrm{ml}$, only slightly reduced cell viability to $88.7 \%$ for the SW1783 cell line and to $77.7 \%$ for the SW1088 cells (Fig. 2). The viability assay for garlic oil was performed using a concentration range of 0.015 to $1.5 \mu \mathrm{g} / \mathrm{ml}$ due to the presence of a separate oil layer at the higher tested concentrations. In contrast to DADS, $1.5 \mu \mathrm{g} / \mathrm{ml}$ garlic oil significantly reduced cell viability in all tested cell lines to $30.9 \%$ in CCF-STTG1, $45.9 \%$ in CHLA-03-AA, 31.1\% in SW1783 and $40.6 \%$ in SW1088 cells (Fig. 3). The $\mathrm{IC}_{50}$ values were $4.05 \mu \mathrm{g} / \mathrm{ml}$ for CCF-STTG1, $0.072 \mu \mathrm{g} / \mathrm{ml}$ for CHLA-03-AA, $1.11 \mu \mathrm{g} / \mathrm{ml}$ for SW1783 and $0.15 \mu \mathrm{g} / \mathrm{ml}$ in SW1088 (Table I). 


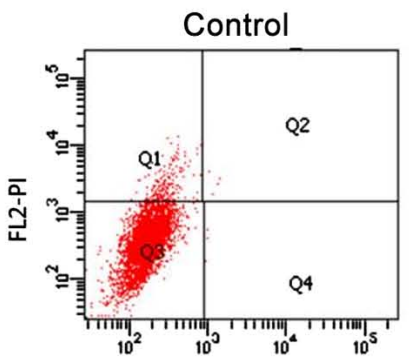

FL1-FITC

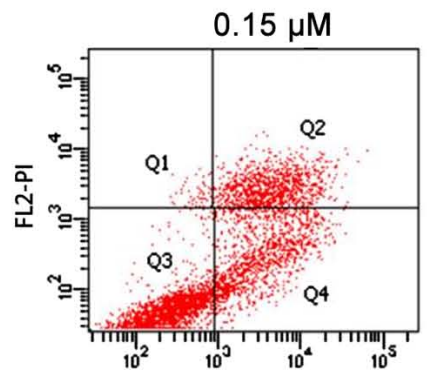

FL1-FITC

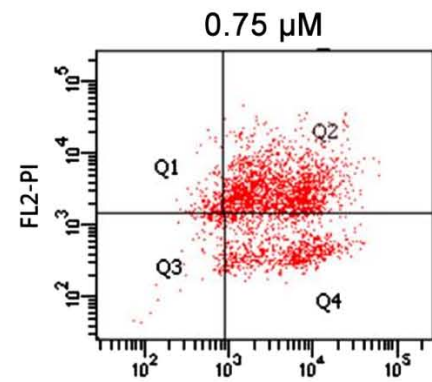

FL1-FITC

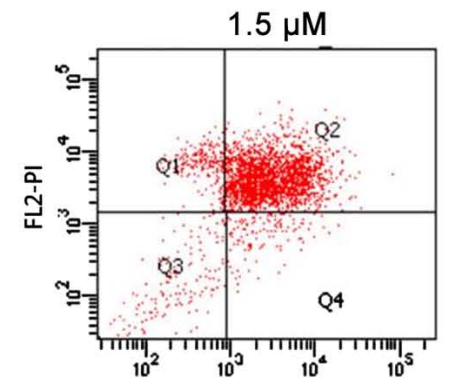

FL1-FITC

Figure 1. Gating strategy used for flow cytometry analysis. Representative examples of fluorescence activated cell sorting dot plots of CCF-STTG1 cells treated with increasing concentrations of garlic oil are presented, and the gating strategy used is also shown. In the quadrant gates, the Q1, Q2, Q3 and Q4 fields correspond respectively to necrotic, late-apoptotic, alive cells and early apoptotic cells. FITC, fluorescein isothiocyanate; PI, propidium iodide.

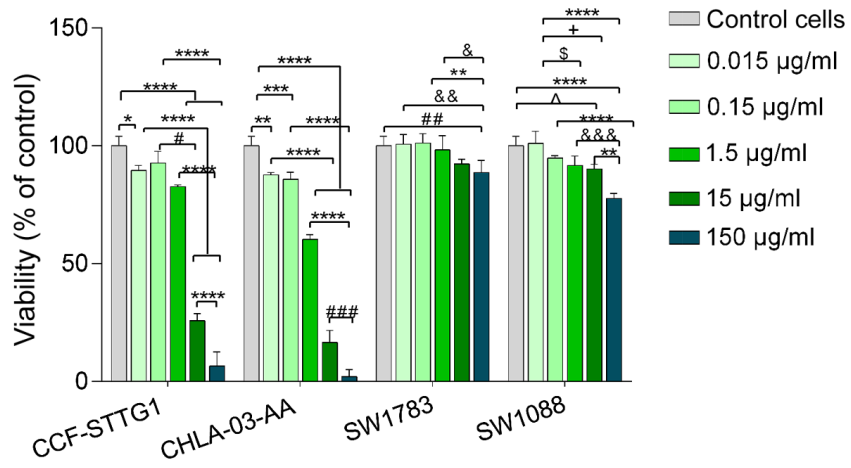

Figure 2. Viability of CCF-STTG1, CHLA-03-AA, SW1783 and SW1088 cells after $24 \mathrm{~h}$ of treatment with increasing concentrations of DADS. Viability is expressed as a percentage of the control cells (untreated cells). Data are presented as the mean \pm standard deviation of 3 repeats. ${ }^{*} \mathrm{P}<0.05$, ${ }^{* *} \mathrm{P}<0.01,{ }^{* * *} \mathrm{P}<0.001,{ }^{* * * *} \mathrm{P}<0.0001 .{ }^{\#} \mathrm{P}<0.05 ;{ }^{\# \#} \mathrm{P}<0.01,{ }^{\# \# \#} \mathrm{P}<0.001 ;{ }^{\&} \mathrm{P}<0.05$,

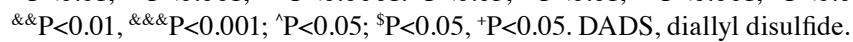

The results of the flow cytometry analysis were consistent with the viability test. There was a significantly higher percentage of live cells observed in the DADS-treated samples for SW1783 and SW1088 cell lines (Fig. 4). For samples treated with $1.5 \mu \mathrm{g} / \mathrm{ml}$ garlic oil, the percentages of live cells were 3,10, 15 and 36\% for CCF-STTG1, CHLA-03-AA, SW1783 and SW1088 cells, respectively (Fig. 5). Flow cytofluorimetric analyses were performed to determine the proportion of dead cells using an Annexin V/PI double staining kit. Annexin V signal detection provides a very sensitive method for detecting cellular apoptosis, whereas PI is used to detect necrotic or late apoptotic cells, characterized by the loss of integrity of the plasma and nuclear membranes (13). Data generated by flow cytometry was plotted in 2D dot plots, in which PI was represented vs. Annexin V-FITC. These plots were divided into four regions corresponding to: i) Viable cells which were negative to both probes; ii) apoptotic cells which were PI negative and Annexin-V positive; iii) late apoptotic cells which were PI and Annexin-V positive; and iv) necrotic cells which were PI positive and Annexin- $V$ negative. For each condition tested, 10,000 cells were analyzed, and the percentage of alive, early apoptotic, late apoptotic and necrotic cells was expressed as a percentage of the total number of cells assessed. Flow cytometry analysis showed that DADS induced both, apoptotic

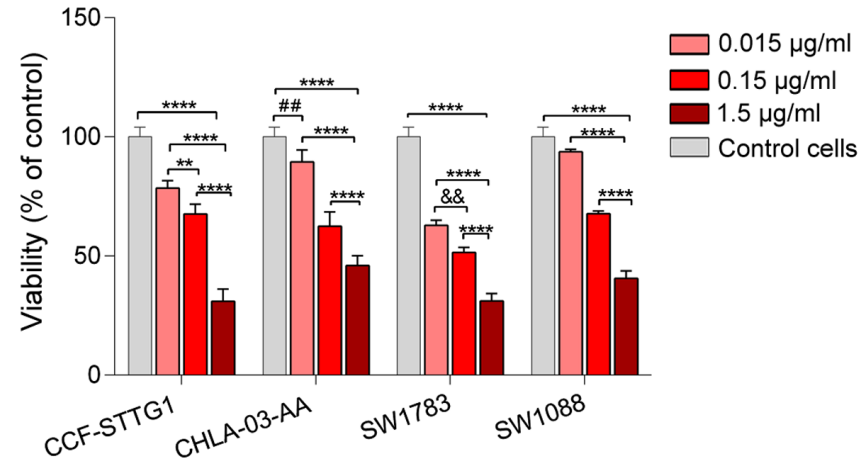

Figure 3. Viability of CCF-STTG1, CHLA-03-AA, SW1783 and SW1088 cells after $24 \mathrm{~h}$ of treatment with increasing concentrations of garlic oil. Viability is expressed as a percentage of the control cells (untreated cells). Data are presented as the mean \pm standard deviation of 3 repeats. ${ }^{* *} \mathrm{P}<0.01$, ${ }^{* * * *} \mathrm{P}<0.0001 ;{ }^{\# \#} \mathrm{P}<0.01 ;{ }^{\& \&} \mathrm{P}<0.01$.

and necrotic cell death at a similar level in the four tested glioma cell lines (Fig. 4). Using $1.5 \mu \mathrm{g} / \mathrm{ml}$, DADS induced apoptosis in $28 \%$ of CCF-STTG1 cells and necrosis in $30 \%$ of these cells. For SW1783 cells, $15 \%$ of the cells were apoptotic and $15 \%$ of the cells were necrotic. For SW1088 cell, $13 \%$ of the cells were apoptotic and $11 \%$ were necrotic. In CHLA-03-AA cells, $43 \%$ of the cells were apoptotic cells and $19 \%$ of the cells were necrotic. Garlic oil notably induced apoptotic death in all the tested cell lines at a low concentration. A dose of $0.75 \mu \mathrm{g} / \mathrm{ml}$ resulted in $78,43,54$ and $34 \%$ proportion of apoptotic cells in the CCF-STTG1, CHLA-03-AA, SW1783 and SW1088 cells, respectively. At a concentration of $1.5 \mu \mathrm{g} / \mathrm{ml}$ garlic oil, 78, 74, 59 and $57 \%$ of the CCF-STTG1, CHLA-03-AA, SW1783 and SW1088 cells were apoptotic, respectively (Fig. 5).

\section{Discussion}

The prominent effects of garlic on cell-cycle arrest, apoptosis and differentiation has been the subject of several studies (14-16). At present, there have been no attempts to analyze the effects of the compounds derived from garlic on glioma of varying degrees of differentiation, to the best of our knowledge. Hong et al (17) examined the effect of DAS and DADS on H460 (p53-wild type) and H1299 (p53-null) non-small cell lung cancer cells. Both DAS and DADS induced 
CCF STTG1

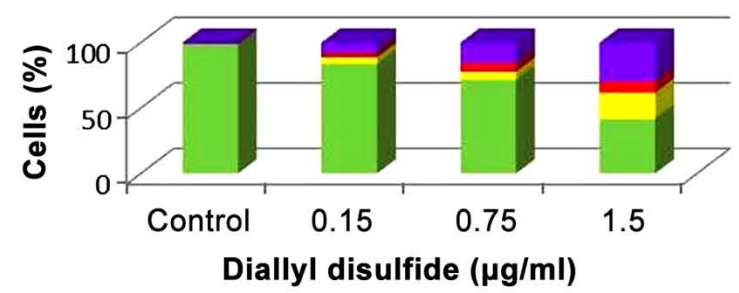

CHLA-03-AA

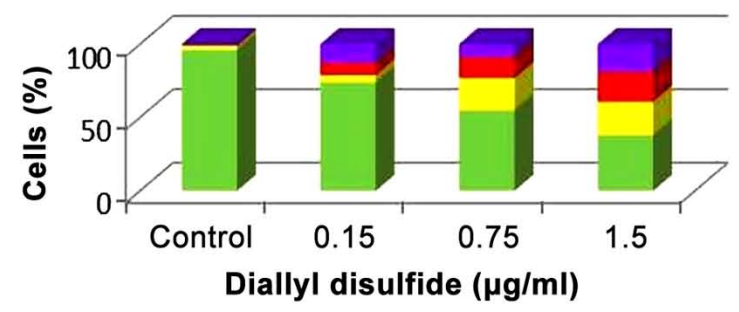

SW1783

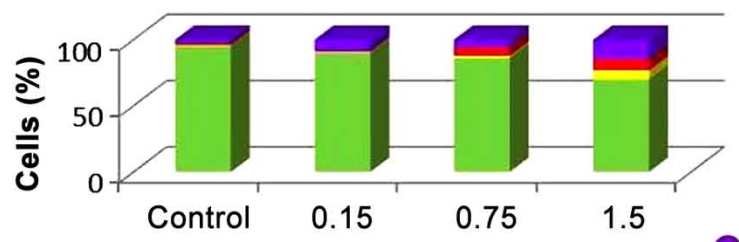

Diallyl disulfide $(\mu \mathrm{g} / \mathrm{ml})$

SW1088

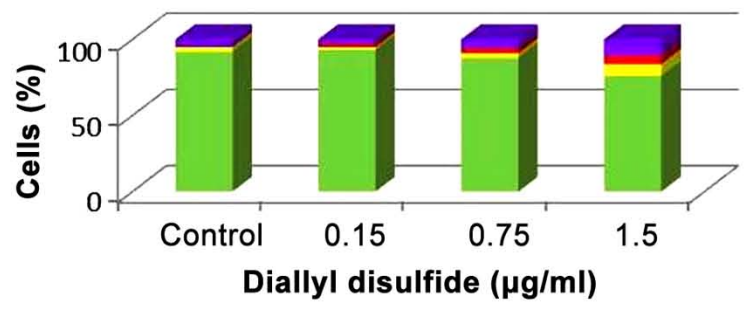

Figure 4. Flow cytometry analysis evaluating the type of induced cell death in CCF-STTG1, CHLA-03-AA, SW1783 and SW1088 cells after incubation with increasing concentrations of diallyl disulfide. Control cells were incubated in cell culture medium without any treatment.

CCF STTG1

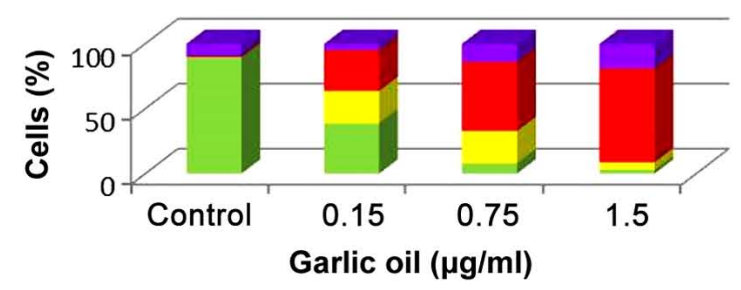

CHLA-03-AA

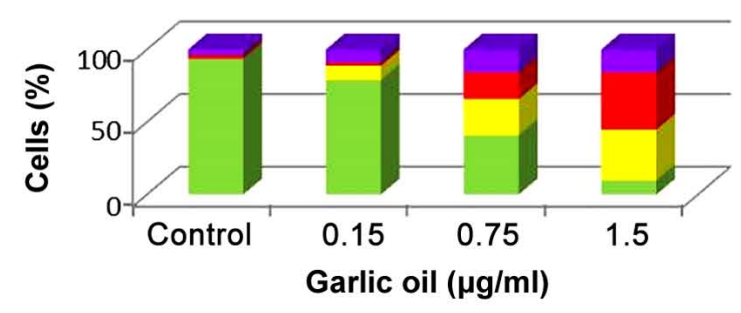

SW1783

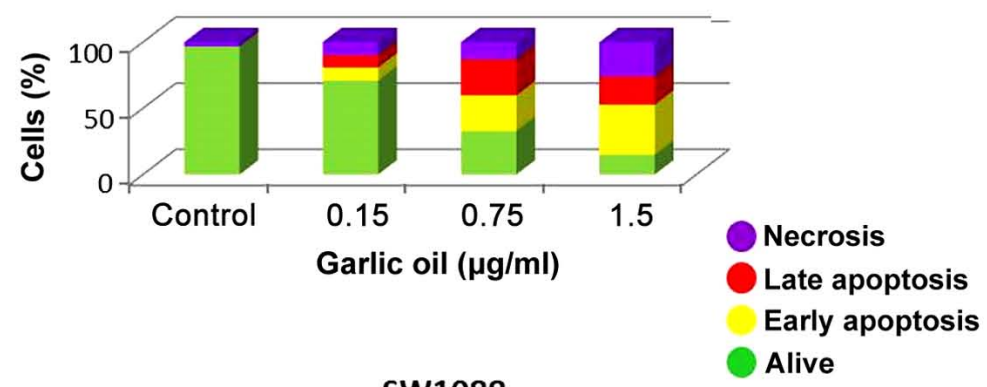

SW1088

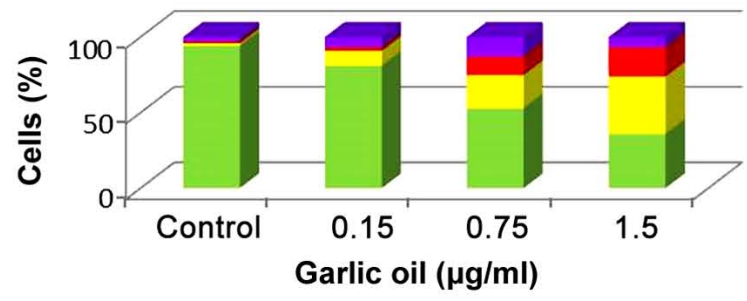

Figure 5. Flow cytometry analysis evaluating the type of induced cell death in CCF-STTG1, CHLA-03-AA, SW1783 and SW1088 cells after incubation with increasing concentrations of garlic oil. Control cells were incubated in cell culture medium without any treatment.

apoptosis in the non-small cell lung cancer cells, which was correlated with a marked increase in the protein expression levels of $\mathrm{p} 53$ and Bax, as well as a decrease in Bcl-2 protein expression (17). Nakagawa et al (18) examined the inhibitory effect of DADS on human estrogen receptor-positive and -negative breast cancer cell lines. In both these breast cancer cell lines, DADS resulted in a significant increase in Bax and caspase-3 protein expression, resulting in apoptotic cell death. In addition, DADS in the estrogen receptor-negative cells acted synergistically with eicosapentaenoic acid, which is a tumor cell suppressor. Similarly, in vivo, DADS resulted in a reduction of tumor weight compared to the DADS-untreated mice (18).
The toxic effects of DADS and garlic oil were assessed on four glioma cells in the present study. The results showed that DADS did not result in cytotoxicity at any of the assessed concentrations in SW1783 and SW1088 cells. In the CCF-STTG1 and CHLA-03-AA cells, there was a significant reduction in cell viability observed after treatment with 15 and $150 \mu \mathrm{g} / \mathrm{ml}$. The lack of toxicity at lower doses of DADS and the cytotoxic effects at higher doses of DADS were consistent with the results of Koh et al (19). In a previous study performed on PC-12 cells (cells derived from a transplantable rat pheochromocytoma), it was shown that the lowest tested concentration of DADS, $20 \mu \mathrm{M}$, exhibited neuroprotective 
effects by inducing an increase in Akt kinase activity, triggering the PI3K/Akt signaling pathway and decreasing the activity of proapoptotic factors (cytochrome $c$, caspase 3 and PARP protein) (20). Lower concentrations of DADS exhibited cytoprotective potential, whereas $50 \mu \mathrm{M}$ of DADS resulted in an increase in the levels of free radicals and lipid peroxidation of PC-12 cell membranes. Furthermore, $100 \mu \mathrm{M}$ DADS inhibited the PI3K/Akt pathway and increased proapoptotic activity (21). The high degree of invasiveness of gliomas may be due to aberrant signal transduction of pathways downstream of PI3K and Akt/PKB kinases, which are responsible for the regulation of cell proliferation, differentiation and survival (22-24). Mutations of genes encoding the above enzymes are commonly observed in gliomas, and lead to an increase in their activity, resulting in increased resistance to chemotherapy (25). The absence of a cytotoxic effect on SW1783 and SW1088 cells following incubation with DADS may be due to the enhanced resistance exhibited by these cell lines caused by mutations in the PI3K-Akt/PKB-mTOR signaling pathway gene (26). It is likely that for the CHLA-03-AA and CCF-STTG1 cells, higher doses of DADS induced cytotoxicity by decreasing Akt/PKB factor activity, a mechanism that was observed by Koh et al (19). Apoptosis inhibition via the Akt/PKT signaling pathway is very complex and can occur at different levels of the signal transduction pathways initiating programmed cell death. PI3K/AKT kinase phosphorylates the pro-apoptotic BAD protein and promotes the binding of BAD to the cytoplasmic 14-3-3 protein, resulting in inhibition of apoptosis (22). Das et al (27) demonstrated that the garlic compounds DAS, DADS and DATS are effective in inducing apoptosis in human glioblastoma T98G and U87MG cells. It was suggested that the compounds present in garlic activate multiple pathways which result in induction of apoptosis in these cells by increasing the production of reactive oxygen species (ROS). They have shown that ROS induces apoptosis via the phosphorylation of $\mathrm{p} 38$ MAPK and activation of the redox-sensitive JNK1 pathway. Production of ROS in these cells also increased endoplasmic reticulum stress, and mitochondrial release of cytochrome C and Smac into the cytosol, which also result in apoptosis (27). Liu et al (28) showed that different variants of the glutathione S-transferase (GST) genes may affect the pathogenesis of glioma, and thus may have an impact on the variable responses to the various types of therapeutic compounds in gliomas with distinct variants of these genes. The aforementioned differences in GST gene variants may underlie the disparities observed in DADS-induced cytotoxicity in the present study. However, multi-center controlled prospective studies are required to verify this assumption.

Garlic oil contains several active substances that possess a high therapeutic potential. These include diallyl, allyl methyl and dimethyl mono- to hexa-sulfides (29). Furthermore, the biological effects of garlic can be attributed to all of the characteristic organosulfur compounds that it contains (30). Thus, it is hypothesized that the substances contained in garlic oil may amplify the induction of apoptotic cell death by activating different pathways to DADS, which induced apoptosis only in two tested cell lines, while garlic oil caused activation of apoptotic death pathways in all four tested cell lines. Additionally, only $0.75 \mu \mathrm{g} / \mathrm{ml}$ garlic oil was required to induce apoptosis. The anti-cancer potential of garlic oil remains poorly understood. The majority of the studies in this field of study have been performed on blood cancer cell lines (31-33). Seki et al (31) examined the effects of garlic oil on HL-60 cells (a human promyelocytic leukemia cell line). They found that garlic oil markedly reduced cell proliferation and concluded that it could induced differentiation of HL-60 cells into granulocytic cells (31). The preliminary results of the present study are promising, particularly the results obtained for garlic oil, which induced a significant cytotoxic effect in all tested astrocytoma cell lines of various degrees of differentiation. In addition, garlic oil primarily induced activation of apoptosis. It is crucially important for therapeutic applications used for the treatment of brain tumors to reduce cell death, where necrotic death is undesirable due to a resultant strong inflammatory reaction (34).

The present study has several limitations that should be addressed in subsequent studies. These include assessing the mechanism of the induced apoptotic pathway, estimation of cell-cycle phase distribution, as well as the examination of the effects of tested compounds on normal human cells. It is hypothesized that the PI3K-Akt/PKB-mTOR signaling pathway may be induced following treatment of glioma cells with DADS and garlic oil. However, it is necessary to assess the mechanisms leading to apoptosis in astrocytoma cells following treatment with active substances derived from garlic in more detail. The effects of other compounds from garlic oil and their antiproliferative properties on glioma cells should also be addressed. This can be used to identify and separate the most active substances from the mixture. Additionally, it would be useful to perform similar research with normal cells to identify the substances which exhibit selectivity against malignant cells.

\section{Acknowledgements}

Not applicable.

\section{Funding}

This work was supported by a grant for Young Scientists sponsored by Statutory Funds of Wroclaw Medical University and supported by the Polish Ministry of Science and Higher Education, (grant no. STM.A040.18.013). Funding for the cell lines was provided by Dermamed company.

\section{Availability of data and materials}

The datasets used and/or analyzed during the present study are available from the corresponding author on reasonable request.

\section{Authors' contributions}

$\mathrm{AC}$ and PS designed the study. AC performed the experiments and acquired the data. AC, JK and JS analyzed and interpreted the data. AC and JS wrote the first draft. AC, JS and JK contributed to writing or critical revision of the manuscript. All authors have read and approved the final version of the manuscript.

\section{Ethics approval and consent to participate}

Not applicable. 


\section{Patient consent for publication}

Not applicable.

\section{Competing interests}

The authors declare that they have no competing interests.

\section{References}

1. Wang K, Groom M, Sheridan R, Zhang S and Block E: Liquid sulfur as a reagent: Synthesis of polysulfanes with 20 or more sulfur atoms with characterization by UPLC-(Ag+)-coordination ion spray-MS. J Sulfur Chem 34: 55-66, 2013.

2. Osuka S and Van Meir EG: Overcoming therapeutic resistance in glioblastoma: The way forward. J Clin Invest 127: 415-426, 2017.

3. Yi L and Su Q: Molecular mechanisms for the anti-cancer effects of diallyl disulfide. Food Chem Toxicol 57: 362-370, 2013.

4. Druesne N, Pagniez A, Mayeur C, Thomas M, Cherbuy C, Duée $\mathrm{PH}$, Martel $\mathrm{P}$ and Chaumontet $\mathrm{C}$ : Repetitive treatments of colon HT-29 cells with diallyl disulfide induce a prolonged hyperacetylation of histone H3 K14. Ann NY Acad Sci 1030: 612-621, 2004

5. Huang YS, Xie N, Su Q, Su J, Huang C and Liao QJ: Diallyl disulfide inhibits the proliferation of HT-29 human colon cancer cells by inducing differentially expressed genes. Mol Med Rep 4 553-559, 2011.

6. Arunkumar A, Vijayababu MR, Srinivasan N, Aruldhas MM and Arunakaran J: Garlic compound, diallyl disulfide induces cell cycle arrest in prostate cancer cell line PC-3. Mol Cell Biochem 288: 107-113, 2006.

7. Munday R and Munday CM: Relative activities of organosulfur compounds derived from onions and garlic in increasing tissue activities of quinone reductase and glutathione transferase in rat tissues. Nutr Cancer 40: 205-210, 2001.

8. Ropero S and Esteller M: The role of histone deacetylases (HDACs) in human cancer. Mol Oncol 1: 19-25, 2007.

9. Myzak MC, Ho E and Dashwood RH: Dietary agents as histone deacetylase inhibitors. Mol Carcinog 45: 443-446, 2006.

10. Druesne-Pecollo N and Latino-Martel P: Modulation of histone acetylation by garlic sulfur compounds. Anticancer Agents Med Chem 11: 254-259, 2011.

11. Wlodkowic D, Telford W, Skommer J and Darzynkiewicz Z: Apoptosis and beyond: Cytometry in studies of programmed cell death. Methods Cell Biol 103: 55-98, 2011.

12. Thomson M and Ali M: Garlic [Allium sativum]: A review of its potential use as an anti-cancer agent. Curr Cancer Drug Targets 3: 67-81, 2003.

13. Petrovic V, Nepal A, Olaisen C, Bachke S, Hira J, Søgaard CK, Røst LM, Misund K, Andreassen T, Melø TM, et al: Anti-cancer potential of homemade fresh garlic extract is related to increased endoplasmic reticulum stress. Nutrients 10: 450, 2018.

14. Ariga T and Seki T: Antithrombotic and anticancer effects of garlic-derived sulfur compounds: A review. Biofactors 26: 93-103, 2006.

15. Herman-Antosiewicz A and Singh SV: Checkpoint kinase 1 regulates diallyl trisulfide-induced mitotic arrest in human prostate cancer cells. J Biol Chem 280: 28519-28528, 2005.

16. Hosono T, Fukao T, Ogihara J, Ito Y, Shiba H, Seki T and Ariga T: Diallyl trisulfide suppresses the proliferation and induces apoptosis of human colon cancer cells through oxidative modification of beta-tubulin. J Biol Chem 280: 41487-41493, 2005.

17. Hong YS, Ham YA, Choi JH and Kim J: Effects of allyl sulfur compounds and garlic extract on the expression of Bcl-2, Bax, and p53 in non small cell lung cancer cell lines. Exp Mol Med 32: $127-134,2000$
18. Nakagawa H, Tsuta K, Kiuchi K, Senzaki H, Tanaka K, Hioki K and Tsubura A: Growth inhibitory effects of diallyl disulfide on human breast cancer cell lines. Carcinogenesis 22: 891-897, 2001.

19. Koh SH, Kwon H, Park KH, Ko JK, Kim JH, Hwang MS Yum YN, Kim OH, Kim J, Kim HT, et al: Protective effect of diallyl disulfide on oxidative stress-injured neuronally differentiated PC12 cells. Brain Res Mol Brain Res 133: 176-186, 2005.

20. Borek C: Antioxidant health effects of aged garlic extract. J Nutr 131 (3 Suppl): 1010S-1015S, 2001.

21. Pedraza-Chaverri J, González-Orozco AE, Maldonado PD, Barrera D, Medina-Campos ON and Hernández-Pando R: Diallyl disulfide ameliorates gentamicin-induced oxidative stress and nephropathy in rats. Eur J Pharmacol 473: 71-78, 2003.

22. Cheng CK, Fan QW and Weiss WA: PI3K signaling in glioma-animal models and therapeutic challenges. Brain Pathol 19: 112-120, 2009.

23. Fan QW, Cheng CK, Nicolaides TP, Hackett CS, Knight ZA, Shokat KM and Weiss WA: A dual phosphoinositide-3-kinase alpha/mTOR inhibitor cooperates with blockade of epidermal growth factor receptor in PTEN-mutant glioma. Cancer Res 67: 7960-7965, 2007

24. Opel D, Westhoff MA, Bender A, Braun V, Debatin KM and Fulda S: Phosphatidylinositol 3-kinase inhibition broadly sensitizes glioblastoma cells to death receptor- and drug-induced apoptosis. Cancer Res 68: 6271-6280, 2008.

25. Mueller W, Mizoguchi M, Silen E, D'Amore K, Nutt CL and Louis DN: Mutations of the PIK3CA gene are rare in human glioblastoma. Acta Neuropathol 109: 654-655, 2005.

26. Jia S, Liu Z, Zhang S, Liu P, Zhang L, Lee SH, Zhang J, Signoretti S, Loda M, Roberts TM and Zhao JJ: Essential roles of PI(3)K-p110beta in cell growth, metabolism and tumorigenesis. Nature 454: 776-779, 2008.

27. Das A, Banik NL and Ray SK: Garlic compounds generate reactive oxygen species leading to activation of stress kinases and cysteine proteases for apoptosis in human glioblastoma T98G and U87MG cells. Cancer 110: 1083-1095, 2007.

28. Liu W, Long H, Zhang M, Wang Y, Lu Q, Yuan H, Qu Q and Qu J: Glutathione S-transferase genes variants and glioma risk: A case-control and meta-analysis study. J Cancer 19: 4679-4688, 2019.

29. Bayan L, Koulivand PH and Gorji A: Garlic: A review of potential therapeutic effects. Avicenna J Phytomed 4: 1-14, 2014.

30. Omar SH and Al-Wabel NA: Organosulfur compounds and possible mechanism of garlic in cancer. Saudi Pharm J 18: 51-58, 2010.

31. Seki T, Tsuji K, Hayato Y, Moritomo T and Ariga T: Garlic and onion oils inhibit proliferation and induce differentiation of HL-60 cells. Cancer Lett 160: 29-35, 2000.

32. Toledano Medina MÁ, Merinas-Amo T, Fernández-Bedmar Z Font R, Del Río-Celestino M,Pérez-Aparicio J,Moreno-Ortega A, Alonso-Moraga Á and Moreno-Rojas R: Physicochemical characterization and biological activities of black and white garlic: In vivo and in vitro assays. Foods 8: 220, 2019.

33. Liang R, Huang GS, Wang Z, Chen XQ, Bai QX, Zhang YQ, Dong BX and Wang WQ: Effects of human bone marrow stromal cell line (HFCL) on the proliferation, differentiation and apoptosis of acute myeloid leukemia cell lines U937, HL-60 and HL-60/VCR. Int J Hematol 87: 152-166, 2008.

34. Yang Y, Jiang G, Zhang P and Fan J: Programmed cell death and its role in inflammation. Mil Med Res 2: 12, 2015.

This work is licensed under a Creative Commons Attribution-NonCommercial-NoDerivatives 4.0 International (CC BY-NC-ND 4.0) License. 